\title{
Editorial:
}

\section{Choosing a Strategy for Maintaining Health Against the Possibility of Changing the Internal Environ- ment and Social Stress}

\author{
Mohammad Reza Vaez-Mahdavi ${ }^{*}$ (D) \\ 1. Department of Physiology, School of Medicine, Shahed University, Tehran, Iran.
}

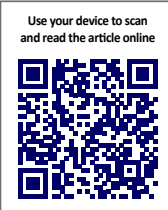

Crtation Vaez-Mahdavi MR. Choosing a Strategy for Maintaining Health Against the Possibility of Changing the Internal Environment and Social Stress. Immunoregulation. 2020; 2(2):67-68. http://dx.doi.org/10.32598/Immunoregulation.1.4.185

doif ${ }^{\circ}$ http://dx.doi.org/10.32598/Immunoregulation.1.4.185

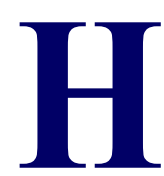

umans, in facing changes in the internal environment or the social environment, often ask themselves what strategy to choose against these changes, strategies that guarantee optimal health in their physical, psychological, and social dimensions. If no immediate answer is found for this question, the brain is in trouble to find the preferences in choosing the possible options, and thus, the concept of social stress is formed [1]. Also, when the choices include concurrent benefits and risks, the context of the stressful processes in the brain is created.

To encounter such conditions, the body aims to maintain internal stability and, by activating the Hypothalamic-Pituitary-Adrenal axis (HPA), tries to manage stress. Glucocorticoids, in turn, facilitate the acquisition of information for the central nervous system by reducing the threshold for brain cells stimulation. Thus the brain will spend energy and gain more information on a new level of preferences in strategy selection scenarios. However, when there are no preferences for choosing a scenario for the brain, stressful conditions continue, and the HPA axis activity will result in changes in immunoregulation [2].
Today, people live in very stressful societies. Studies have established an association between the increased prevalence of diseases and social and physiological stresses [3]. Studies on both normal and induced stresses have shown their significant effects on the immune response [4-6]. Animal studies have found that increased incidence of aggressive behaviors is due to the higher cytokine production and cellular immune activity [7]. Based on the type of stimulus and duration of contact, chronic stress influences both innate and acquired immune responses. Stress affects the immune system by activating the HPA axis.

It also affects the innate immune agents, such as monocyte, macrophage, and pro-inflammatory cytokines by increasing stress hormones (glucocorticoids and catecholamines). Chronic stress influences the acquired immune components by changing the immune cell population and disturbing the balance between immune cells and released cytokine levels [8-12]. These conditions also increase the likelihood of developing infectious diseases by influencing immune responses and allow the emergence of new diseases or the return of some old eradicated diseases.

The onset of metabolic syndrome, obesity, increased cholesterol, and diabetes is also known as other compli- 
cations of brain exposure with no preferences, long-term uncertainty, and chronic social stress. For example, all known complications of diabetes may be due to longterm encounter to social stress. Hypertension, cardiovascular disease, increased risk of various types of cancers may be due to impairment of the regulation of cytokines and caspases, and disturbances in detecting and preventing mutations are other complications of the uncertain brain and social stress.

Recently, we have focused on monitoring the health of chemical victims of Sardasht City, Iran, regarding their socioeconomic status in causing complications, symptoms, and their response to the treatment. So that the socioeconomic status of chemical victims has been classified and observed in five levels, similar exposure to mustard gas (which was carried out during the Iran-Iraq war in 1995) it has been impressive to the clinical symptoms of patients in 2017. Also, the difference in biological age and actual age in people exposed to Iraq chemical attacks in Sardasht City has been found, which indicates that this long-term stress has led to premature aging in the affected patients.

We are going to discuss the issues of close and bilateral relationships, lack of selective preferences, deprivation, social inequalities, and the impairment of the regulation of various safety systems based on the results of our previous study and other studies in a detailed review article. We hope that this article is presented in the upcoming issue of the immunoregulation journal.
[5] Biondi M. Effects of stress on immune functions: An overview. Psychoneuroimmunology. 2001; 2:189-226.

[6] Rabin BS. Stress, immune function, and health: The connection, 1st edition. Hoboken, New Jersey: Wiley-Liss; 1999.

[7] Petitto JM, Gariepy J-L, Gendreau PL, Rodriguiz R, Lewis MH, Lysle DT. Differences in NK cell function in mice bred for high and low aggression: Genetic linkage between complex behavioral and immunological traits? Brain, Behavior, and Immunity. 1999; 13(2):175-86. [DOI:10.1006/ brbi.1998.0539] [PMID]

[8] Aghajani M, Mahdavi MRV, Najafabadi MK, Ghazanfari T. The effect of social stress on chronic pain perception in female and male mice. PLOS one. 2012; 7(10):e47218. [DOI:10.1371/journal.pone.0047218] [PMID] [PMCID]

[9] Bailey MT, Kierstein S, Sharma S, Spaits M, Kinsey SG, Tliba $\mathrm{O}$, et al. Social stress enhances allergen-induced airway inflammation in mice and inhibits corticosteroid responsiveness of cytokine production. The Journal of Immunology. 2009; 182(12):7888-96. [DOI:10.4049/jimmunol.0800891] [PMID] [PMCID]

[10] Dhabhar FS. A hassle a day may keep the pathogens away: The fight-or-flight stress response and the augmentationof immune function. Integrative and Comparative Biology. 2009; 49(3):215-36. [DOI:10.1093/icb/icp045] [PMID]

[11] Hu D, Wan L, Chen M, Caudle Y, LeSage G, Li Q, et al. Essential role of IL-10/STAT3 in chronic stress-induced immune suppression. Brain, Behavior, and Immunity. 2014 36:118-27. [DOI:10.1016/j.bbi.2013.10.016] [PMID] [PMCID]

[12] Silberman D, Ayelli-Edgar V, Zorrilla-Zubilete M, Zieher L, Genaro A. Impaired T-cell dependent humoral response and its relationship with $\mathrm{T}$ lymphocyte sensitivity to stress hormones in a chronic mild stress model of depression. Brain, Behavior, and Immunity. 2004; 18(1):81-90. [DOI:10.1016/ S0889-1591(03)00109-0]

\section{Reference}

[1] Peters A, McEwen BS, Friston K. Uncertainty and stress: Why it causes diseases and how it is mastered by the brain. Progress in Neurobiology. 2017; 156:164-88. [DOI:10.1016/j. pneurobio.2017.05.004] [PMID]

[2] Hitze B, Hubold C, Van Dyken R, Schlichting K, Lehnert H, Entringer S, et al. How the selfish brain organizes its supply and demand. Frontiers in Neuroenergetics. 2010; 2:7. [DOI:10.3389/fnene.2010.00007] [PMID] [PMCID]

[3] Moradi F, Vaez Mahdavi MR, Ahmadiani A, Rogani M, Altarihi T, Delshad A, et al. Unstable social situation and food inequality can promote accumulation of lipofuscin and induced apoptosis in hepatocytes. Koomesh. 2012, 14(1):55-64.

[4] Azpiroz A, Garmendia L, Fano E, Sanchez-Martin JR. Relations between aggressive behavior, immune activity, and disease susceptibility. Aggression and Violent Behavior. 2003; 8(4):433-53. [DOI:10.1016/S1359-1789(02)00066-6] 